\title{
Portal vein injury due to blunt abdominal trauma
}

\author{
N Ramathavha, ${ }^{1} \mathrm{MB}$ ChB, Dip For Med (SA); A B van As, ${ }^{2} \mathrm{MB}$ ChB, FCS (SA), MMed, MBA, PhD \\ ${ }^{1}$ Department of Forensic Pathology, Pietersburg and Mankweng hospitals, University of Limpopo, Polowane, South Africa \\ ${ }^{2}$ Department of General Surgery, Pietersburg and Mankweng hospitals, University of Limpopo, Polokwane, South Africa
}

Corresponding author: N Ramathavha (dearndivhuwo@gmail.com)

Portal vein injuries associated with blunt abdominal force trauma are associated with high mortality. The fatal outcome may be related to various factors, including clinical state at presentation, concurrent injuries and surgical skill during laparotomy. A case of portal vein injury following blunt abdominal trauma sustained in a motor vehicle accident is described.

S Afr Med J 2021;111(11b):1147-1148. https://doi.org/10.7196/SAMJ.2021.v111i11b.16130

The portal vein is formed by union of the superior and inferior mesenteric veins together with the splenic vein behind the liver. ${ }^{[1]}$ Injury to the portal vein is considered rare but carries a high mortality rate. ${ }^{[2]}$ We describe a case of portal vein injury following blunt abdominal trauma sustained in a motor vehicle accident. We review case clinical records and postmortem findings.

\section{Case \\ Clinical history}

A 19-year-old woman was referred to our tertiary hospital from a peripheral hospital as a polytrauma case following a motor vehicle accident. She had been a passenger on the back of a 'bakkie' on the day of referral. Injuries sustained included abdominal wall abrasions, two open abdominal wounds with disembowelment, as well as multiple long-bone fractures (right humerus and left tibia). On presentation she was fully conscious with a Glasgow Coma Scale score of 15/15. Her blood pressure was $90 / 60 \mathrm{mmHg}$, her heart rate was $100 \mathrm{bpm}$, her respiratory rate was $26 / \mathrm{min}$ and she maintained saturation at $97 \%$ on room air. She was fully resuscitated with intravenous fluids and blood products. She was booked for an exploratory laparotomy, wound washout and abdominal wall repair.

The procedure was performed on the day of presentation and extended into the next day. Intraoperatively, the inferior epigastric vessels and branch of common iliac vein were noted to be actively bleeding and were ligated. The abdominal organs including the liver and spleen were reported as intact. The abdomen was washed out and an intra-abdominal drain was left.

Postoperatively the patient was kept in theatre because there was no intensive care bed available. She developed hypotension and tachycardia. She subsequently died 24 hours postoperatively in the operating theatre while still awaiting admission to the intensive care unit.

As per the Inquest Act ${ }^{[3]}$ and Health Professions Amendment Act ${ }^{[4]}$ of the South African legislature, this death is considered unnatural. This case was referred by the South Africa Police Services (SAPS) to the forensic pathology laboratory for postmortem examination. The examination was performed approximately 24 hours post mortem.

\section{Postmortem findings}

Therapeutic measures included laparotomy wound, wound suturing (stapling), intra-abdominal drain placement and orthopaedic backslabs supporting the fractured limbs.
Body surface findings:

- There was a large vertical brush abrasion on the left outer side of the torso.

- There were stapled wounds on the lower abdomen.

- Large area of bruising around the upper aspect of the left thigh around the hip joint.

Internal organ findings:

- The peritoneal cavity contained $600 \mathrm{~mL}$ of blood (both fluid and clotted blood). The clotted blood was predominantly localised at the right upper abdominal quadrant.

- There was an incomplete laceration of the portal vein (Fig. 1). This was associated with surrounding clotted haematoma. The haematoma extended around the porta hepatis and into the lesser sac of the stomach (Fig. 2). The gallbladder and the external biliary tracts were intact. The liver was pale with patchy haemorrhagic areas.

Other significant findings included shocked lungs and pale kidneys.

The loops of intestine, the bowel mesentery and the spleen were unremarkable.

\section{Discussion}

Portal vein injuries are considered rare injuries with a high mortality. ${ }^{[2]}$ The mortality rate of traumatic portal vein injury has been reported to range from $50 \%$ to $70 \%{ }^{[5]}$

More commonly, the mechanism of traumatic portal vein injury is penetrating force, either gunshot wound or stab wound, with a minority of cases as a result of blunt force trauma. ${ }^{[2,5]}$ The outcome of blunt force portal vein injuries has been noted to be better than that of penetrating force injuries. ${ }^{[1]}$

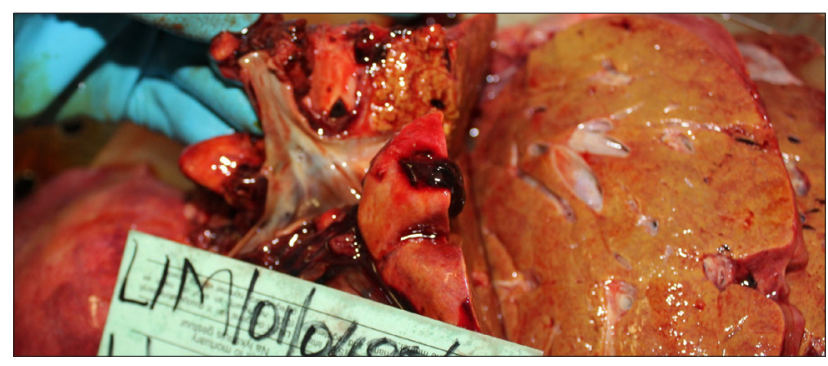

Fig. 1. Visceral surface of the liver showing the incomplete laceration of the portal vein and cut section of the right liver lobe. 


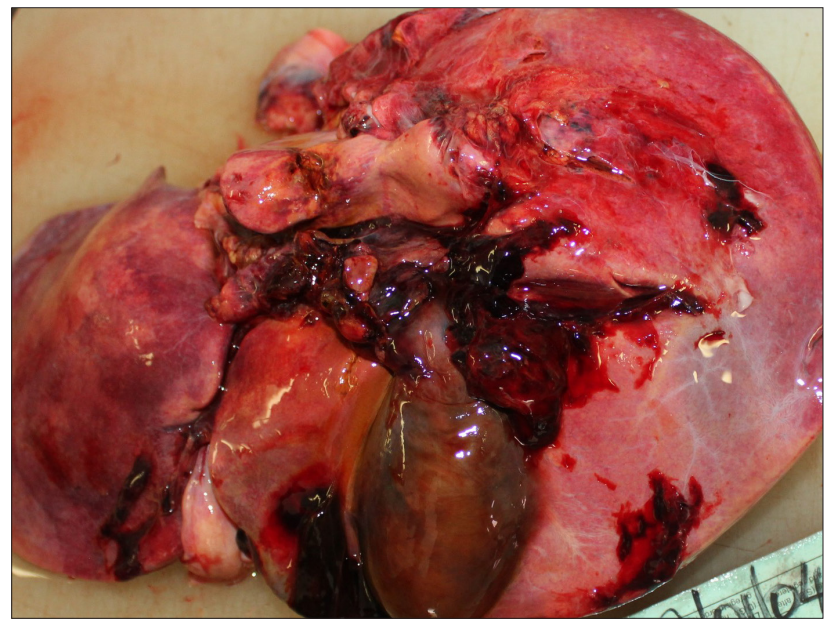

Fig. 2. Visceral surface of the liver showing haematoma around the porta herpatis.

Motor vehicle accidents are reported as common causes of blunt abdominal trauma. ${ }^{[1,6]}$ Our case was not an exception to the noted trend as she had been a passenger in a motor vehicle accident.

Blunt injuries to major abdominal vessels are rare. ${ }^{[7]}$ Death associated with major abdominal vascular injury has been reported to be associated with the technical difficulty of isolating the injured vessels, and the commonly encountered haemorrhage obscuring the surgical field. ${ }^{[2]}$ The high mortality associated with portal vein injury has been noted to be related to the difficulty in controlling haemorrhage. ${ }^{[1]}$

Hypotension or the presence of shock at the time of admission has reportedly been associated with increased risk of mortality. ${ }^{[2]}$ In addition, the presence of additional extra-abdominal injuries increases the risk of mortality owing to blunt abdominal trauma. ${ }^{[8]}$ Blunt abdominal trauma secondary to motor vehicle accidents does not occur in isolation; the presence of extra-abdominal injury may also distract managing clinicians from serious abdominal pathology. ${ }^{[6]}$

Our patient presented in a state of circulatory shock with a systolic blood pressure of $90 \mathrm{mmHg}$. There were also extra-abdominal and additional injuries including multiple limb fractures, which may have increased the risk of mortality.

Various modalities may be used in assessment of patients with blunt abdominal trauma. These include physical examination, diagnostic peritoneal lavage, computed tomography (CT) scan, ultrasonography, laparoscopy and laparotomy ${ }^{[9]}$ The choice of modality to be applied in assessing the injuries would depend on the availability of resources and the clinical state of the patient. Hypotension is one of the indications for emergency laparotomy for blunt abdominal trauma, performed among other indications for haemorrhage control. ${ }^{[10]}$
In the present case, emergency laparotomy was performed and bleeding vessels that were identified were ligated; solid and hollow viscus injuries were ruled out.

When diagnosed and identified, traumatic portal vein injuries are considered most difficult to manage and are more commonly associated with other upper abdominal injuries including injuries to the hepatic artery and extrahepatic biliary duct. ${ }^{[5,11]}$

In our case, despite intra-abdominal organ exploration during laparotomy, portal vein injuries were missed or not recognised. Missed abdominal injuries carry a high mortality and require complete surgical exploration and early re-operation in cases with multiple injuries. ${ }^{[12]}$ The majority of deaths following blunt force trauma are reported to be due to unrecognised abdominal injuries or under-appreciation of the severity of abdominal injuries. ${ }^{[13]}$

\section{Conclusion}

Portal vein injury following blunt force trauma to the abdomen may be a very rare event; however, full abdominal examination and exploration during laparotomy to exclude such injury should be performed. There should be a low threshold for early re-exploration in cases of persistent postoperative hypotension.

Declaration. None.

Acknowledgements. None.

Author contributions. ABvA supervised the article written by NR.

Funding. None.

Conflicts of interest. None.

1. Philips B, Mirzaie M, Turco L. Portal vein injuries: A review. J Emerg Trauma Care 2017;2(2):4.

2. Fraga GP, Bansal V, Fortlage D, Coimbra R. A 20 year experience with portal and superior mesenteric venous injuries: Has anything changed? Eur J Vasc Endovasc Surg 2008;37:87-91. https://doi. $\operatorname{rg} / 10.1016 / j . j v s .2008 .11 .109$

South Africa. Inquest Act No. 58 of 1959.

4. South Africa. Health Professions Amendment Act No. 29 of 2007.

Pearl J, Chao A, Kennedy S, Paul B, Rhee P. Traumatic injuries to the portal vein: Case study. J Trauma 2002;56(4):779-782. https://doi.org/10.1097/01.ta.0000053467.36120.fa

6. Howes N, Walker T, Allorto NL, Oosthuizen GV, Clarke DL. Laparotomy for blunt abdominal trauma in civilian trauma service. S Afr J Surg 2012;50(2):30-32.

7. Stamatatos I, Theodorou M, Mataxas E, et al. Zone 1 vascular abdominal trauma: Damage control and staged management. Clin Surg 2018;3:1905.

8. Pimentel SK, Sawczyn GV, Mazepa MM, Goncalves Da Rosa FG. Risk factors for mortality in blunt abdominal trauma with surgical approach. Revista do Colégio Brasileiro de Cirurgiôes 2015;42(4):259264. https://doi.org/10.1590/0100-69912015004011

9. Malhotra AK, Ivatury RR, Latifi R. Blunt abdominal trauma: Evaluation and indication for laparotomy. Scand J Surg 2002;91:51-57. https://doi.org/10.1177/145749690209100108

10. Dharap SB, Noronha J, Kumar V. Laparotomy for blunt abdominal trauma: Some uncommon indications. J Emerg Trauma Shock 2016;9(1):32-36. https://doi.org/10.4103/0974-2700.173866

11. Mattox KL, Espada R, Beall CA. Traumatic injury to the portal vein. Ann Surg 1975;181(5):519-522. Mattox KL, Espada R, Beall CA. Traumatic injury to
https://doi.org/10.1097/00000658-197505000-00003

12. Sung CK, Kim KH. Missed injuries in abdominal trauma. J Trauma Injury Infect Crit Care 1996:41(2):276-278. https://doi.org/10.1097/00005373-199608000-00013
. Sung CK, Kim KH. Mised injuries in abdominal trauma J Traum

13. West JG, Trunkey DD, Lim RC. Systems of trauma care: A study of two countries. Arch Surg 1979;114(4):455-460. https://doi.org/10.1001/archsurg.1979.01370280109016

Accepted 16 September 2021 